\title{
FORS, a new histo-blood group: A current review
}

\author{
Sara Brito ${ }^{1 *}$, Camilla Hesse ${ }^{2 *}$ and Fernando Mendes ${ }^{1,3,4,5 *}$ \\ ${ }^{1}$ Polytechnic Institute of Coimbra, Coimbra Health School, Biomedical Laboratory Sciences, Portugal \\ ${ }^{2}$ Department for Clinical Chemistry and Transfusion Medicine, Institute for Biomedicine, Sahlgrenska Academy, University of Gothenburg, Sweden \\ ${ }^{3}$ CNC.IBILI, University of Coimbra, Portugal \\ ${ }^{4}$ Biophysics and Biomathematics Institute, IBILI-Faculty of Medicine, University of Coimbra, Portugal \\ ${ }^{5}$ CIMAGO, FMUC-Faculty of Medicine, University of Coimbra, Portugal \\ \#Both authors contributed equally to the manuscript
}

\begin{abstract}
Carbohydrate histo-blood groups in man include the AB0, H, I, Lewis, $\mathrm{P}_{1} \mathrm{P}_{\mathrm{K}}$, and GLOB systems in which glycoproteins and glycolipids carry immunodominant terminal sugars, defining polymorphic antigens $(\mathrm{Ag})$. Blood group compatibility is one of the most important procedures to correctly transfuse ensuring quality and ensuring patient safety.

Forssman glycosphingolipid (FORS) Ag blood group system was demonstrated biochemically on the red blood cells of two blood donors from different families with the $A_{p a e}$ phenotype, first described in 1987. Afterwards, a group of Swedish researchers found several criteria that make it up the FORS blood group becomes an independent blood group. In 2012, International Society of Blood Transfusion concluded that subgroup $A_{\text {pae }}$ should be abolished and a new histo-blood group should be created.

Several antigens, including Fs (Forssman), may act as receptors for certain pathogens, emerging naturally antibody (Ab) against various microorganisms, making these $\mathrm{Ab}$ a barrier in transfusion/transplantation medicine.

It is known that the Fs synthesis in uroepithelial cells could make such individuals more susceptible to infection by E.coli and the expression of Fs Ag has been reported in cancer cells, being a cancer epitope of interest.

Therefore, it's extremely important the study of this histo-blood group, considering all its potentialities, contributing to a better characterization of this histo-blood group.
\end{abstract}

\section{Introduction}

Carbohydrate histo-blood group antigen (Ag), first recognized on red blood cells (RBC) around 1900, have been suggested to be part of our innate immune response. Major carbohydrate histo-blood groups in man include the $\mathrm{AB} 0, \mathrm{H}$, I, Lewis, $\mathrm{P}_{1} \mathrm{P}_{\mathrm{K}}, \mathrm{H}$ and GLOB systems in which glycoproteins and glycolipids carry immunodominant terminal sugars, defining polymorphic Ag. Other mammals also express carbohydrate histo-blood groups, such as AB0, and Fs but their expression on RBCs varies among species [1].

This review is focused in a new histo-blood group, the FORS blood group system, acknowledged by International Society of Blood Transfusion (ISBT) in 2012, with transfusion and biological significance.

\section{Material and methods}

This study consists of a review of the literature concerning a new histo-blood group and the implications in transfusion, the relation with microorganisms and cancer.

The information survey was obtained from online databases such as PubMed. For the literature review the following keywords were used: FORS System; Anti-Fs; Forssman expression; kodocytes, $\mathrm{KODE}^{\mathrm{TM}}$ Technology.
An initial trial of papers of interest was performed by the relevance of the title and content of abstract. Pre-selected articles were completely analysed and properly selected. Selection was performed based on the inclusion criteria: papers in English; review articles or original research papers available in free full text; importance for the achievement of this review, as history, genetics, the relation between FORS System with microorganisms and its importance in cancer. Exclusion criteria were established as unavailability of selected papers in free full text and papers published before 2007.

\section{FORS blood group system}

FORS is a new blood group system comprising a single Ag, namely FORS described in Table 1. FORS was demonstrated biochemically on the RBCs of two blood donors from different families with the $A_{p a e}$ phenotype, first described in 1987 [2].

Correspondence to: Fernando Mendes, Biomedical Laboratory Sciences Department, ESTeSC-Coimbra Health School, Rua 5 de Outubro - SM Bispo, 3046-854 Coimbra, Portugal, E-mail: FJMendes@estescoimbra.pt

Key words: forssman, blood groups, antibodies

Received: February 02, 2017; Accepted: February 15, 2017; Published: February 18,2017 
Table 1. FORS - Blood Group Terminology according to the International Society of Blood Transfusion.

\begin{tabular}{|l|l|l|l|l|l|l|l|l|l|l|l|l|}
\hline ISBT System number & System name & System symbol & Antigen name & Antigen symbol & Gene name & Chromosome location \\
\hline 031 & FORS & FORS & FORS1 & FORS1 & GBGT1 \\
\hline
\end{tabular}

ISBT: International Society of Blood Transfusion

The expression of the Ag occurs not only in RBCs but also in other types of cells. Therefore, the blood group Ag are also called histo-blood group Ag [3].

\section{History}

The Forssman Ag was first discovered in 1911 by John Frederick Forssman after injecting rabbits with a suspension of kidney tissue from guinea pig and the rabbits were able to produce $\mathrm{Ab}$ that haemolysed sheep RBCs [4].

In 1987, three families with a supposed AB0 subgroup named $A_{p a e}$ were identified. The $A_{p a e}$ positive family members showed a divergent $\mathrm{Ab}$ and lectin reaction pattern of the RBCs. The Helix pomatia lectin resulted in a strong reaction, polyclonal $\mathrm{Ab}$ anti-A gave a weak response and monoclonal $\mathrm{Ab}$ anti- $\mathrm{A}$ were nonreactive, thus presenting an apparent paradox $[1,5]$.

Several years later a group of Swedish researchers showed that, Fs glycolipid, usually only found in the RBCs of non-primate mammals, was strongly expressed in human RBCs of the subgroup $A_{p a e}[1]$.

Lola et al. found a single point mutation in the GBGT1 gene that makes the human Fs synthase activity and gives origin to a rare phenotype that was previously misclassified as an AB0 subgroup, $A_{p a e}$, and referred that the Fs glycolipid is transmitted hereditarily $[1,2,6]$.

To define a new blood-group Ag, the ISBT requires to be shown independent of all other blood group Ag, being expressed on RBCs, and inheritable $[1,2]$. These criteria are all fulfilled by the Fs glycolipid.

Therefore, ISBT concluded that subgroup $A_{p a e}$ should be abolished and a new histo-blood group should be created: FORS blood group system, acknowledged by ISBT in 2012 as blood group system number $31[1,2]$.

\section{Genetics}

Initial studies dating back to 1911 demonstrated that expression of the Forssman $\mathrm{Ag}$ is species specific: the $\mathrm{Ag}$ is expressed in some mammals (e.g., sheep, dogs, horses, chickens, etc.) but not in others (rabbits, pigs, humans, etc.), referred to as FORS positive species and FORS negative species, respectively $[4,7,8]$.

Nowadays, it is known that the FORS is expressed on RBCs and it has been found in guinea pigs, horses, hamsters, sheep and chickens but could be also found in other body fluids, in cells, several human tissues and organs and is heritable [1,2,4,7].

The presence of FORS on human RBCs is unusual and was shown to be the result of an enzyme activating amino acid substitution arising from a missense mutation in the human Fs synthase gene [2,6].

DNA sequence analysis of GBGT1 showed a heterozygous for $887 \mathrm{G}>\mathrm{A}$, which changes arginine at position 296 to glutamine (Arg296Gln). This change allowed the catalyse synthesis of the terminal $3-\alpha-\mathrm{N}$-acetylgalactosamine to its globoside, and the inactive human Fs synthase to become enzymatically active, originating a rare phenotype that was previously misclassified as an $\mathrm{AB} 0$ subgroup $[1,2,6,9]$.

Interestingly, all primates have arginine at position 296 in the enzyme whilst FORS positive animals have glutamine. An independent study also showed the genetic basis of human Forssman negativity and found that Gln296 in the GBGT1-encoded enzyme are crucial for the enzyme activity, whilst the human consensus is Arg296, supporting the role of Arg296Gln as an activating change [2].

In humans, the gene is located on chromosome 9 and consists of 7 exons with the coding region shared between all except the first one. In several species, such as dog, mouse, chicken, turtle, and carp, Fs synthase is active in most tissues. In contrast, in other species, its activity is restricted to erythroid tissue (sheep); or the enzyme is inactive due of point mutations or exon loss (cow, rat, primates) [6].

\section{FORS prevalence}

The frequency of individuals with different blood groups varies widely in different ethnicities and populations [3].

The global frequency of the FORS Ag blood group still is unknown, although it is probably of very low frequency, with most individuals being genetically Forssman Ag negative, and the naturally occurring $\mathrm{Ab}$ can be found in most of FORS negative people [6,10,11].

\section{Human Fs synthase model}

Carbohydrates in the form of glycoproteins and glycolipids play crucial roles in various signalling and molecular recognition processes, affect the stability and structure of proteins, and are epitopes recognized by the immune system [12].

The close homology ( $45 \%$ amino-acid identity) between the structure of $\mathrm{AB} 0$ transferase and GBGT1 gene permitted creation of a 3-dimensional model of the Fs-synthesizing enzyme based on a crystal structure of AB0 transferase [1].

Forssman Ag, synthesized by Fs-synthase, a homologous enzyme of the AB0 transferase (globoside 3- $\alpha$-N-acetyl-Dgalactosaminyltransferase), terminates with $\alpha 3-\mathrm{N}$-acetylgalactosamine, in analogy with blood group A Ag [1,3,4,6,7].

\section{Implications in health and disease}

\section{Antigen}

The Forssman Ag is a glycolipid with the structure GalNAca $(1,3)$ GalNAc $\beta(1,3) \mathrm{Gal} \alpha(1,4) \mathrm{Gal} \beta(1,4) \mathrm{Glc}$, as shown in Figure $1[4,13]$.

\section{Forssman antigen}

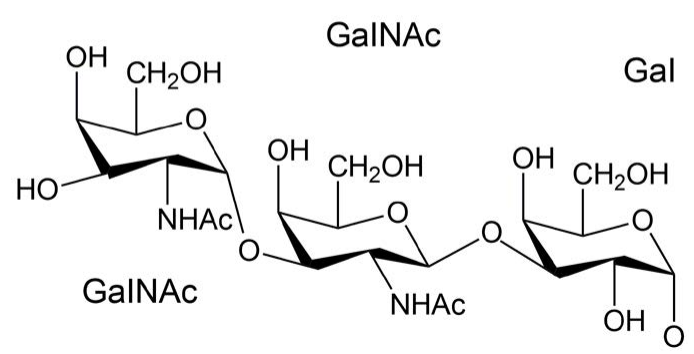

Figure 1. Terminal Structure of the Forssman Antigen. 
Table 2. Summary of the articles included in the review.

\begin{tabular}{|c|c|c|c|}
\hline Reference & Type of study & Population & Results \\
\hline [1] & Experimental study & 2 donnors & $\begin{array}{l}\text { The identification of Fs glycolipids, normally found only on RBCs of selected non-primate mammals, are strongly expressed on human } \\
A_{\text {pae }} \text { RBCs. } \\
A_{\text {pae }} \text { phenotype was redefined as Fs Ag positive and independent of AB0 group, not comparable to weak A subgroups. } \\
\text { Fs Ag is synthesized by Fs synthase (globoside 3- } \alpha \text {-N-acetyl-D-galactosaminyltransferase), an enzyme homologous to the AB0 } \\
\text { transferase. } \\
\text { The Fs synthase gene, } G B G T 1 \text {, in } \mathrm{A}_{\text {pac }} \text { individuals encoded an arginine to glutamine change at residue } 296 \text {. } \\
\text { Transfection experiments and molecular modelling showed that } 296 \mathrm{Gln} \text { reactivates the human Fs synthase, was associated with the Fs- } \\
\text { positive phenotype in } \mathrm{A}_{\text {pac }} \text { families. } \\
\text { Fs is a new histo-blood group system with potential implications for both transfusion/transplantation medicine and pathogen } \\
\text { susceptibility. } \\
\text { Anti-Fs can activate complement and may have the potential to cause intravascular lysis of Fs-positive RBCs. } \\
\text { Uropathogenic } E \text {.coli containing prsG-adhesin-encoding plasmids agglutinated } A_{p a e} \text { but not group } 0 \text { cells, suggesting biological } \\
\text { implications. } \\
\text { Fs Ag may be expressed in carcinomas. }\end{array}$ \\
\hline [2] & Experts opinion & NA & $\begin{array}{l}\text { The presence of Fs results of an enzyme activating amino acid substitution arising from a missense mutation in the human Fs synthase } \\
\text { gene, } G B G T 1 \text {. } \\
\text { Fs was demonstrated biochemically on the RBCs of two blood donors in different families with the } A_{p a e} \text { phenotype. } \\
\text { DNA sequence analysis of } G B G T 1 \text { showed changes arginine at position } 296 \text { to glutamine. } \\
\text { Fs synthase, using the crystal structure of the closely related AB0 transferase. } \\
\text { Fs is not usually found on the RBCs of primates but is highly expressed on the RBCs and uroepithelia of lower mammals such as dogs, } \\
\text { sheep and many others. }\end{array}$ \\
\hline [4] & Experimental study & NA & $\begin{array}{l}\text { The GBGTl gene encoding the Fs glycolipid synthetase. } \\
\text { The antigen is present in various species, but not in others including humans. } \\
\text { Chicken, turtles, and carp express the antigen, whereas goose, pigeon, and frog lack the antigen. Although the Fs antigen was initially } \\
\text { recognized on sheep erythrocytes, the expression on erythrocytes is rare. } \\
\text { In many species its expression is restricted to tissues. } \\
\text { The Fs antigen is a glycolipid with the structure GalNAc } 1 \text { 1->3GalNAc } \beta 1->3 \text { Gal } \alpha 1->4 \mathrm{Gal} \beta 1->4 \mathrm{Glc} \beta 1->1 \mathrm{Cer} \text {. }\end{array}$ \\
\hline [5] & Experts opinion & NA & $\begin{array}{l}\text { Fs, the first new blood group system in this group of recent discoveries came to light as a suspected } \mathrm{AB} 0 \text { subgroup with unusual serology, } \\
\text { named } A_{p a e^{\circ}}\end{array}$ \\
\hline [6] & Review article & NA & $\begin{array}{l}\text { The human FORS blood group system has been acknowledged after a single point mutation was found in the } G B G T l \text { gene that makes the } \\
\text { human Fs synthase active and gives rise to a rare phenotype that was previously misclassified as an AB0 subgroup. } \\
\text { The Fs Ag is extremely rare, and most individuals are Fs- negative. } \\
\text { The Fs GSL is normally expressed on RBCs of some nonprimate mammals; however, in rare cases, it is also expressed on human } \\
\text { erythrocytes. } \\
\text { The majority of normal human sera contain natural anti-Fs Ab, predominantly of IgM class. } \\
\text { Some human carcinomas have also been shown to express Fs antigen in otherwise Fs-negative individuals. } \\
\text { The antigen is synthesized by a1,3-N- acetylgalactosaminyltransferase, encoded by the } G B G T I \text { gene. } \\
\text { In humans, it is located on chromosome } 9 \text { (9q34). } \\
\text { In several species, such as dog, mouse, chicken, turtle, and carp, Fs synthase is active in most tissues. In contrast, in other species, its } \\
\text { activity is restricted to erythroid tissue (sheep). } \\
\text { Fs synthesis in uroepithelial cells could make such individuals more susceptible to infection by E.coli-producing } P r s G \text { adhesins. }\end{array}$ \\
\hline [7] & Experimental study & NA & $\begin{array}{l}\text { The Fs Ag is expressed in some mammals (e.g., sheep, dogs, horses, chickens, etc.) but not in others (rabbits, pigs, humans, etc.), referred } \\
\text { to as Fs-positive species and Fs- negative species, respectively. } \\
\text { The Fs Ag is present in several forms of human cancers (e.g., gastric, colon, lung). } \\
\text { Since the Fs Ag is a tumor-specific Ag closely integrated with cancer biology, it is desirable to have it readily accessible in order to } \\
\text { incorporate it into carbohydrate conjugate vaccines used to target different types of cancer. }\end{array}$ \\
\hline [10] & Experimental study & NA & $\begin{array}{l}\text { The Fs blood group system (originally recognized as the } \mathrm{A}_{\text {pac }} \text { phenotype) was discovered by sporadic activity against polyclonal anti-A } \\
\text { reagents and activity against the lectin Helix pomatia. } \\
\text { The global frequency of the Fs blood group Ag is still not known, although it is probably of very low frequency, with most individuals } \\
\text { being genetically Fs Ag negative. } \\
\text { The Fs Ag can cause in vitro hemolysis and bind uropathogenic E.coli and therefore may be of transfusion and biologic significance. } \\
\text { In the absence of natural Fs-positive RBCs, kodecytes were created with synthetic disaccharide and pentasaccharide Fs function-spacer- } \\
\text { lipid (FSL). }\end{array}$ \\
\hline [11] & Review article & NA & $\begin{array}{l}\text { The Fs Ag was found in individuals with an activated } G B G T l \text { gene, which is normally not active in humans, but in some non-primate } \\
\text { animals. } \\
\text { Most individuals being genetically Fs Ag negative. } \\
\text { An effective immunization strategy in a blood group specific manner by designing vaccines with blood groups epitopes complementary } \\
\text { to the blood groups of the recipients who would thereby develop an enhanced immune response. }\end{array}$ \\
\hline [19] & Experimental study & NA & $\begin{array}{l}\text { The Fs Ag it is a normal constituent of fetal tissues and virtually absent in healthy adults, but it has been detected in elevated levels in } \\
\text { various human lung, breast, and gastric cancer cell lines. }\end{array}$ \\
\hline [20] & Experimental study & $\begin{array}{l}48 \text { cervical } \\
\text { cancer samples }\end{array}$ & $\begin{array}{l}\text { Cancer cells undergo significant changes in carbohydrate expression, and these alterations can be useful as biomarkers and therapeutic } \\
\text { targets. } \\
\text { GalNAca1-3Gal expression was found on } 55 \% \text { of squamous cell carcinomas. } \\
\text { Carbohydrate Ag has become important molecular targets for cancer diagnostics and therapeutics. }\end{array}$ \\
\hline
\end{tabular}

Fs glycolipid is rarely present on human RBCs (there are only 3 known families whose members have FORS Ag on RBCs), but the distribution of FORS Ag on tissues other than erythroid has not been determined yet [6].

These Ag, such as the one's that constitute AB0 blood group, can be used as receptors by pathogens and their expression in tissues and bodily secretions are thus believed to reflect microbial selection. In response to blood-group-mimicking glycan's on bacterial surfaces, naturally occurring $\mathrm{Ab}$ with the capacity to neutralize various microorganisms are formed, performing a target for a variety of microorganisms and toxins [1].

The FORS Ag can cause in vitro haemolysis and bind uropathogenic 
Escherichia coli and therefore may be of transfusion and biological significance [10].

\section{Antibodies against Forssman}

The majority of normal human sera contain natural Anti-Fs (AntiForssman) Ab, predominantly of IgM class but can be IgG, making these an substantial transfusion and transplantation barriers, being able to induce intravascular haemolysis of Fs-positive RBCs [1,6].

These $\mathrm{Ab}$ might have repercussions in transfusion medicine, organ transplantation and even during pregnancies as they can be involved in perinatal haemolytic disease as well of others naturally occurring anticarbohydrate $\mathrm{Ab}[6]$.

\section{FORS system and bacterial infections}

\section{Escherichia coli}

The urinary tract is one of the most common sites of bacterial infection in humans. Lower urinary tract infections (UTI), such as cystitis, are typically characterized by symptoms including urgency, and dysuria. If left untreated, these infections can progress to acute pyelonephritis or kidney infection, which can be associated with additional symptoms such as fever, nausea, vomiting, and flank pain. These infections also carry the risk of possible progression to bacteraemia $[14,15]$.

A Gram-negative bacteria $[15,16]$ and a common inhabitant of the gastrointestinal tract of humans and animals [15], E. coli is a causative agent in the vast majority of UTIs, possess an arsenal of virulence factors, including fimbrial adhesins, toxins, flagella, autotransporter proteins and iron-acquisition systems, which enable the bacteria to colonize the urinary tract $[15,17]$. These infections are exceedingly common in females, affecting about $11 \%$ of women each year $[14,16,18]$.

About $80 \%$ of uropathogenic E. coli express $P$ fimbriae which anchor to the glycolipid of the outer membranes of urothelial cells localized in the kidney. $P$ fimbriae are frequently associated with cases of acute pyelonephritis. The $P$ fimbriae recognize Gal1-4Ga1 and Ga1Na-3Gal1-4Gal as receptors, which contain oligosaccharide sequences in the globo series of glycolipids [16].

$P a p G$ adhesins are subunits of heteropolymeric protein fibers that form $P$ fimbriae, one of the virulence factors present on the surface of some uropathogenic E. coli strains. Three main variants of $P a p G$ have been characterized, including class I, class II, and class III (which is also known as $\operatorname{Prs}$, an abbreviation derived from pap-related sequence, $G$ subunit) [6].

E. coli strains capable of infecting the urinary tracts of canine and other Fs- expressing mammals adhere to uroepithelial cells via Fs-binding $\operatorname{Prs} G$ adhesins. Expression of canine Fs synthase induces binding of canine E. coli strains to human and monkey epithelial cell lines $[1,6]$.

Thus, FORS synthesis in uroepithelial cells could make such individuals more susceptible to infection by E. coli producing $\operatorname{Prs} G$ adhesins $[6,11]$.

\section{FORS system and cancer}

The expression of FORS Ag has been reported in cancer cells and tissues [8], and is a cancer epitope of interest. It is a normal constituent of fetal tissues and virtually absent in healthy adults, but it has been detected in elevated levels in various human lung, breast, and gastric cancer cell lines $[19,20]$. Its expression in tissues might be related with the Ab titre in patient's plasma [2-4,7,21].

Jianhao et al. postulate that the FORS Ag is tumor-specific and it is possible to incorporate it in carbohydrate conjugate vaccines used to target different types of cancer to increase an immune response against the Fs pentasaccharide expressed on cancer cells surface $[7,11]$.

Therefore, carbohydrate Ag can have become important molecular targets for cancer diagnostics and therapeutics $[7,22]$.

\section{Conclusion}

The FORS has been established as a histo-blood group system, probably of very low prevalence. However, the function and role of the FORS Ag in humans is not clear and therefore further studies are of importance to elucidate the role in transfusion, transplantation, microorganism infections and in cancer.

\section{Formatting of funding sources}

This research did not receive any specific grant from funding agencies in the public, commercial, or not-for-profit sectors.

\section{References}

1. Svensson L, Hult AK, Stamps R, Ångström J, Teneberg S, et al. (2013) Forssman expression on human erythrocytes: Biochemical and genetic evidence of a new histoblood group system. Blood 121: 1459-1468. [Crossref]

2. Storry JR, Castilho L, Daniels G, Flegel WA, Garratty G, et al. (2014) Internationa Society of Blood Transfusion Working Party on red cell immunogenetics and blood group terminology: Cancun report (2012). Vox Sang 107: 90-96. [Crossref]

3. Yamamoto F, Cid E, Yamamoto M, Blancher A (2012) ABO research in the modern era of genomics. Transfus Med Rev 26: 103-118. [Crossref]

4. Yamamoto M, Cid E, Yamamoto F (2012) Molecular genetic basis of the human Forssman glycolipid antigen negativity. Sci Rep 2: 975. [Crossref]

5. Storry JR (2014) Five new blood group systems - what next? ISBT Sci Ser 9: 136-140. [Crossref]

6. Kaczmarek R, Buczkowska A, Mikolajewicz K, Krotkiewski H, Czerwinski M (2014) P1PK, GLOB, and FORS Blood Group Systems and GLOB collection biochemical and clinical aspects. Do we understand it all yet? Transfus Med Rev 28: 126-136. [Crossref]

7. Feng J, Hevey R, Ling CC (2011) Synthesis of a Forssman antigen derivative for use in a conjugate vaccine. Carbohydr Res 346: 2650-2662. [Crossref]

8. Müthing J, Meisen I, Zhang W, Bielaszewska M, Mormann M, et al. (2012) Promiscuous Shiga toxin $2 \mathrm{e}$ and its intimate relationship to Forssman. Glycobiology 22: 849-862. [Crossref]

9. Jacob F, Hitchins MP, Fedier A, Brennan K, Nixdorf S, et al. (2014) Expression of GBGT1 is epigenetically regulated by DNA methylation in ovarian cancer cells. $B M C$ Mol Biol 15: 24. [Crossref]

10. Barr K, Korchagina E, Popova I, Bovin N, Henry S (2015) Monoclonal anti-A activity against the FORS1 (Forssman) antigen. Transfusion 55: 129-136. [Crossref]

11. Dotz V, Wuhrer M (2016) Histo-blood group glycans in the context of personalized medicine. Biochim Biophys Acta 1860: 1596-1607. [Crossref]

12. Heissigerova H (2003) Molecular modeling of glycosyltransferases involved in the biosynthesis of blood group A, blood group B, Forssman, and iGb3 antigens and their interaction with substrates. Glycobiology 13: 377-386. [Crossref]

13. Tanaka H, Takeuchi R, Jimbo M, Kuniya N, Takahashi T (2013) Synthesis and biological evaluation of the Forssman antigen pentasaccharide and derivatives by a one-pot glycosylation procedure. Chemistry 19: 3177-3187. [Crossref]

14. Nielubowicz GR, Mobley HL (2010) Host-pathogen interactions in urinary tract infection. Nat Rev Urol 7: 430-441. [Crossref]

15. Bien J, Sokolova O, Bozko P (2012) Role of Uropathogenic Escherichia coli Virulence Factors in Development of Urinary Tract Infection and Kidney Damage. Int $J$ Nephrol 2012: 681473. [Crossref]

16. Minardi D, d'Anzeo G, Cantoro D, Conti A, Muzzonigro G (2011) Urinary tract 
infections in women: etiology and treatment options. Int J Gen Med 4: 333-343. [Crossref]

17. Ulett GC, Totsika M, Schaale K, Carey AJ, Sweet MJ, et al. (2013) Uropathogenic Escherichia coli virulence and innate immune responses during urinary tract infection. Curr Opin Microbiol 16: 100-107. [Crossref]

18. Eto DS, Jones TA, Sundsbak JL, Mulvey MA (2007) Integrin-mediated host cell invasion by type 1-piliated uropathogenic Escherichia coli. PLoS Pathog 3: e100. [Crossref]

19. Lescar J, Sanchez J-F, Audfray A, Coll JL, Breton C, et al. (2007) Structural basis for recognition of breast and colon cancer epitopes Tn antigen and Forssman disaccharide by Helix pomatia lectin. Glycobiology 17: 1077-1083. [Crossref]

20. Li Q, Anver MR, Li Z, Butcher DO, Gildersleeve JC (2010) GalNAcalpha1-3Gal, a new prognostic marker for cervical cancer. Int J Cancer 126: 459-468. [Crossref]

21. Smorodin EP, Kurtenkov OA, Sergeyev BL, Chuzmarov VI, Afanasyev VP (2007) The relation of serum anti-(GalNAc beta) and -para-Forssman disaccharide IgG levels to the progression and histological grading of gastrointestinal cancer. Exp Oncol 29: 6166. [Crossref]

22. Yallapu MM, Jaggi M, Chauhan SC (2012) Curcumin nanoformulations: a future nanomedicine for cancer. Drug Discov Today 17: 71-80. [Crossref]

Copyright: $(02017$ Brito S. This is an open-access article distributed under the terms of the Creative Commons Attribution License, which permits unrestricted use, distribution, and reproduction in any medium, provided the original author and source are credited. 